\title{
Öğrenci Hemşirelerin Genital Hijyen Uygulamaları ve Farkındalıkları
}

\section{Genital Hygiene Practices and Awareness of Student Nurses}

\author{
Sezer Er Güneri ${ }^{1}$, Selma Şen ${ }^{2 *}$ \\ ${ }^{1}$ Ege Üniversitesi Hemşirelik Fakültesi, İzmir, Türkiye \\ ${ }^{2}$ Manisa Celal Bayar Üniversitesi Sağlık Bilimleri Fakültesi, Manisa, Türkiye \\ e-mail: er.sezer@hotmail.com, selmasen77@gmail.com \\ ORCID: 0000-0002-6097-841X \\ ORCID: 0000-0002-5009-8363 \\ *Sorumlu Yazar / Corresponding Author: Selma Şen \\ Gönderim Tarihi / Received: 24.02.2019 \\ Kabul Tarihi / Accepted: 28.05.2020 \\ DOI: $10.344087 /$ cbusbed.531635

\section{Öz}

Giriş ve Amaç: Çalışma, öğrencilerin genital hijyen uygulamaları ve farkındalıkları belirlemek amacıyla yapılmıştır. Gereç ve Yöntemler: Tanımlayıcı ve kesitsel olarak planlanan araştırma, Ocak-Mayıs 2017 tarihleri arasında bir kamu üniversitesinin Hemşirelik Fakültesinde çalışmaya katılmaya gönüllü ikinci ve üçüncü sınıfta öğrenim gören 374 öğrenci ile yürütülmüştür. Verilerin toplanmasında araştırmacılar tarafindan oluşturulan toplam 36 sorudan içeren anket formu kullanılmıştır. Verilerin değerlendirilmesinde ortalama, standart sapma, sayılar ve yüzdelik kullanılmıştır.

Bulgular: Öğrencilerin \%14,4'ünün her zaman üreme organlarını hastalık belirtileri yönünden dikkatlice izledikleri, \%7,5'inin her zaman üreme organların temizliği konusunda sağlık görevlilerinden bilgi aldığ, \% $88,8^{\prime}$ 'inin her zaman mensturasyonda hazır ped kullandıkları, \%56,1'inin her zaman mensturasyonda duş şeklinde banyo yaptığ1, \%83,2'sinin her zaman ped değiştirdikten sonra ellerini yıkadıkları, \%89,0'unun her zaman tuvalete girdikten sonra ellerini yıkadıkları, \%11.5'inin her zaman üreme organlarını önden arkaya doğru yıkadıkları, \%77,3'ünün her zaman taharetlendikten sonra tuvalet kağıdı ile kurulandığı; \%40,1'inin bazen pis kokulu akıntı olduğunda ve \%17.4'ünün her zaman üreme organlarında kaşıntı olduğunda doktora gittikleri saptanmıştır.

Sonuç: Öğrencilerin genital hijyene konusunda yetersiz olduğu, genital hijyen davranışları, bilgi alma, yardım aramada yeterli olmadığı ve bu konudaki farkındalıkları düşük olduğu sonucuna varılmıştır.

Anahtar kelimeler: Genital hijyen, genital enfeksiyon, öğrenci hemşire

\footnotetext{
Abstract

Objective: This study was conducted in order to determine the students of the importance of genital hygiene practices. Materials and Methods: The study was designed as a descriptive and cross-sectional study. Research is planned in descriptive and cross-sectional type. The research was conducted between January and May, 2017, with 374 students studying at the Faculty of Nursing of a public university. Questionnaire form which consisting of 36 questions was used in order to collect data. The data were evaluated with numbers, percentages, mean, standard deviation was used. Results: It was determined that $14,4 \%$ of the students always watch the reproductive organs carefully in terms of symptoms, 7,5\% always received information from health professionals on the cleaning of the reproductive organs, $88,8 \%$ of them always use pad ready for menstruation, 56,1\% always had a bath in the form of a shower in the menstruation, $83,2 \%$ always wash their hands after changing the pad, $89.0 \%$ always wash their hands after entering the toilet, $11.5 \%$ always wash their reproductive organs from front to back, $77,3 \%$ is always used toilet paper, $40,1 \%$ of the students went to the doctor when they had a bad smelling flow and $17.4 \%$ went to the doctor whenever there was itching in the sexual.

Conclusion: It has been determined that the students are inadequate about genital hygiene and are inadequate about genital hygiene behavior and help in search and the awareness on this issue is low.

Keywords: Genital hygiene, genital infection, nursing students
} 


\section{Giriș}

Vajinal enfeksiyonlar, kadınların cinsel ve aile yaşamları üzerinde olumsuz etkileri olan önemli bir sağlı sorunudur. Kadınları jinekoloji polikliniğinde tıbbi yardım almaya iten başlıca nedenler arasında yer alan vajinal enfeksiyonların dünya çapında yaygınlığı artırmaktadır [1]. Farklı toplum seviyelerinde yapılan çalışmalarda anormal vajinal akıntının prevalansı $\% 12,1$ ile \%30 arasında değişmektedir $[1,2,3,4,5]$. Vajinal enfeksiyonlar için bilinen risk faktörleri arasında hamilelik, kötü hijyen (perineal hijyen ve adet hijyeni), uzun süreli antibiyotik veya steroid tedavisi, diyabetes mellitus, immün yetmezlik, sigara ve alkol tüketimi, kontrasepsiyon, vajinal tamponlar, çoklu partnerler ve sık cinsel ilişki, uygun olmayan koşullar altında doğum ve kürtaj, çok rrklılık ve düşük sosyoekonomik durum ve yetersiz beslenme yer almaktadır [6].

Genital hijyen, kadınların üreme sağlığını korumada en önemli etkenlerden birisidir Vajinal enfeksiyon oluşmasında birçok faktörün yanı sıra, kadının genital hijyene gösterdiği özenin önemi iyi bilinmektedir. Genital hijyene dikkat edilmediğinde, genital enfeksiyona yatkınlı artmakta, enfeksiyon tedavi edilmediği takdirde ise kadının doğurganlığını etkileyebilmekte, ilerleyerek pelvik inflamatuvar hastalığa neden olabilmektedir [2, 7, 8, 9, 10,11]. Genital enfeksiyonlara karşı koruyucu önlemlerin alınması kadın üreme sağlığının korunması ve geliştirilmesi ilk basamağını oluşturmaktadır. Bu nedenle erken tanı ve tedavi hizmetlerinin yapılması ve sağlık personelinin bu konuda eğitim ve danışmanlık rollerini yapması önemlidir.

Üreme sağlığı hizmetleri kapsamında hemșireler, vajinal akıntının tanımlanması, enfeksiyon nedeni olabilecek yanlış hijyen alışkanlıklarının saptanması, doğru sağlık davranışlarının geliştirilmesi, patolojik durumların ayırt edilebilmesi, önerilen tetkik ve tedavilerin yürütülmesinde ve danışmanlık hizmetlerinde aktif rol almaktadırlar [2, 4, 11, 12] Öğrenci hemşirelerin, genital hijyen ile ilgili doğru uygulamaları bilerek uygulamaları ve sağlıklı yaşam biçimi davranışına dönüştürmeleri hem birey olarak kendi sağlıklarını, hem de bilgili ve bilinçli hemşire olarak hizmet sunacakları toplumun sağlığını koruma ve geliştirmede oldukça önemlidir $[4,13]$. Bu nedenler doğrultusunda çalışma, öğrencilerin genital hijyen uygulamaları ve farkındalıkları belirlemek amacıyla yapılmıştır.

\section{Materyal ve Metot}

Araştırma 2016-2017 eğitim ve öğretim yılının bahar döneminde bir kamu üniversitesinin Hemşirelik Fakültesi'nde kesitsel tipte, tanımlayıcı olarak yapılmıştır. Araştırmanın evrenini ilgili fakültenin ikinci sınıf (278) ve üçüncü sınıf öğrencileri $(\mathrm{n}=475)$, toplam 753 öğrenci oluşturmuştur. Araştırmanın örneklemi evreni bilenen örneklem formülü ile $\% 95$ güven aralığında en az 255 öğrencinin alınması gerektiği hesaplanmıştır. Ocak-Mayıs 2017 tarihlerde toplam 374 öğrenci ile araştırma tamamlanmıştır.

Araştırmada veri toplama aracı olarak, ilgili literatür doğrultusunda hazırlanan ve 36 sorudan oluşan "Anket Formu" kullanılmıştır. Anket formunda, ilk 11 soruda öğrencilerin sosyo demografik özellikleri (yaş, cinsiyet vb.) ile ilgili bilgileri, devamında da öğrenci hemşirelerin genital hijyen uygulamaları ve farkındalıkları sorgulanmıştır.

Araştırmanın uygulanabilmesi için Hemşirelik Fakültesi Dekanlığı'ndan izin alınmıştır. Veriler, araştırmanın yapılacağı kurumdan yazılı izinler alındıktan sonra OcakMayıs 2017 tarihleri arasında, 20-30 dakikada araştırmacılar tarafından toplanmıştır. Görüşme öncesi, öğrencilere araştırmanın amacı, araştırmadan sağlanacak yararlılıklar, görüşme için harcayacağı zaman konusunda açılamalar yapılmış ve sözlü onamları alınmıştır.

Verilerin değerlendirilmesinde SSPS paket programından yararlanılarak ortalama, standart sapma, sayılar ve yüzdelik kullanılmıştır.

\section{Bulgular ve Tartışma}

Öğrencilerin tanıtıcı özelliklerine göre dağılımları incelendiğinde; öğrencilerin, \%67,9'unun 21-23 yaş grubunda ve yaş ortalamalarının $20,88 \pm 0,89$ olduğu, $\% 99,2$ 'sinin bekar, \%81,3'ünün Anadolu ya da fen lisesi, $\% 42,8$ 'inin ilçe, $\% 87,2$ 'sinin çekirdek ailede yaşadığı, $\% 70,3$ 'ünün gelirini gidere denk algıladığı, $\% 93,3$ 'ünün sosyal güvencesinin olduğu saptanmıştır. Öğrencilerin annelerinin \%67,4'ü okur-yazar/ilkokul mezunu, babalarının ise \%43,9'u okur-yazar/ilkokul mezunu, $\% 43,9$ 'u ortaokul/lise mezunu olduğu belirlenmiștir. Öğrencilerin iç çamaşır türünün \%74,9'unun pamuklu, $\% 25,1$ 'inin pamuklu ve naylon/saten olduğu; \%53,5'inin her gün, \%44,4'ünün iki günde bir kez, \%2,1'inin haftada bir kez iç çamaşırlarını değiştirdiği; iç çamaşırlarını \%5,9'unun kendi elinde, \%89,8'inin çamaşır makinesinde, \%4,3'ünün ücretli çamaşırhanede temizlediği; iç çamaşırlarını \%69,5'inin deterjan, $\% 26,7$ 'sinin çamaşır suyu+deterjan, $\% 3,7$ 'sinin sabunla yıkadığı saptanmıştır (Tablo 1).

Tablo 2'de araştırma kapsamına alınan öğrencilerin üreme sağlığına yönelik farkındalık durumlarının dağıllımları görülmektedir. Öğrencilerin \%15,8'inin hiçbir zaman, \%65,8'inin bazen, \%12,0'sinin s1k s1k, \%6,4'ünün her zaman cinsel sağlığı ilgilendiren konularda yapılan eğitim toplantılarına katıldıkları; \%3,2'sinin hiçbir zaman, \%39,0'unun bazen, $\% 43,3$ 'ünün sık sık, \%14,4'ünün her zaman üreme organlarını hastalık belirtileri yönünden dikkatlice izlediği; \%6,7'sinin hiçbir zaman, \%53,7'sinin bazen, $\% 31,3$ 'ünün sık sık, \%8,3'ünün her zaman cinsel sağlıkla ilgili yazılı ve görsel basında çıan haberleri takip ettikleri; \%17,4'ünün hiçbir zaman, \%55,9'unun bazen, $\% 19,3$ 'ünün sik sık, \%7,5'inin her zaman üreme organların temizliği konusunda sağlık görevlilerinden bilgi aldığı saptanmıştır (Tablo 3). 
Tablo 1. Öğrencilerin Genital Hijyen Davranışlarının Dağılımı

\begin{tabular}{|l|c|c|}
\hline Özellikler & n & \% \\
\hline İç Çamaşır Türü & & \\
\hline Pamuklu & 280 & 74.9 \\
Pamuklu ve & 94 & 25.1 \\
naylon/saten & & \\
\hline İç Çamaşır & & \\
Değiştirme Sıklı̆̆ı & 200 & 53.5 \\
\hline $\begin{array}{l}\text { Her gün } \\
\text { İki günde bir kez }\end{array}$ & 166 & 44.4 \\
\hline Haftada bir kez & 8 & 2.1 \\
\hline İç çamaşırlarını & & \\
temizleme şekli & & \\
Kendi elimde & 22 & 5.9 \\
Çamaşırmakinesinde & 336 & 89.8 \\
Ücretli çamaşırhanede & 16 & 4.3 \\
\hline İç çamaşırlarını & & \\
temizlemede & & \\
kullanılan malzeme & 260 & 69.5 \\
\hline $\begin{array}{l}\text { Deterjan } \\
\text { Çamaşır }\end{array}$ & 100 & 26.7 \\
suyu+deterjan & 14 & 3.7 \\
Sabunla yıkama & & \\
\hline TOPLAM & $\mathbf{3 7 4}$ & $\mathbf{1 0 0 . 0}$ \\
\hline
\end{tabular}

Öğrencilerin \%88,8'inin her zaman mensturasyonda hazır ped kullandıkları; \%79,7'sinin hiçbir zaman mensturasyonda bez kullanmadıkları; \%36,9'unun bazen günlük ped/ara bezi kullandıkları; \%56,1'inin her zaman mensturasyonda duş şeklinde banyo yaptığ $1, \% 34,0$ 'ünün her zaman ped değiștirmeden önce ellerini yıkadıkları; $\% 83,2$ 'sinin her zaman ped değiştirdikten sonra ellerini yıkadıkları; \%21,9'unun her zaman tuvalete girmeden önce ellerini yıkadıkları; \%89,0'unun her zaman tuvalete girdikten sonra ellerini yıkadıkları; \%11,5'inin her zaman üreme organlarını önden arkaya doğru yıkadıkları; $\% 77,3$ 'ünün her zaman taharetlendikten sonra tuvalet kâğıdı ile kurulandığı; \%21,4'ünün her zaman pis kokulu akıntı olduğunda ve \%17,4'ünün her zaman üreme organlarında kaşıntı olduğunda doktora gittikleri saptanmıştır.

Genital enfeksiyonların önlenmesinde genital hijyen anahtar role sahiptir. Genital enfeksiyonların önlenmesi için, doğru genital hijyen davranışlarının kazandııılması gerekmektedir [4,9]. Bu yüzden kadınların kişisel hijyen uygulamalarından kaynaklanan risklerin saptanmasının oldukça önemlidir. Pamuklu iç çamaşırları teri emdiklerinden perine bölgesinin kuru kalmasını sağlayarak genital yol enfeksiyonlarına engel olmaktadır [14]. Calıșmada pamuklu iç çamaşırı kullanma 3/4 oranında $(\% 74,9)$ olduğu görülmektedir. Öğrencileri genital hijyenlerinin değerlendirildiği çalışmalarda öğrencilerin pamuklu iç çamaşırı kullanma oranının \%72 ile $\% 93$ arasında olduğu saptanmıştır $[1,4,14,15]$.

Tablo 2. Öğrencilerin Üreme Sağlığına Yönelik Farkındalık Durumu

\begin{tabular}{|c|c|c|c|c|c|c|c|c|}
\hline & \multicolumn{2}{|c|}{$\begin{array}{l}\text { Hiçbir } \\
\text { zaman }\end{array}$} & \multicolumn{2}{|c|}{ Bazen } & \multicolumn{2}{|c|}{ Sık sık } & \multicolumn{2}{|c|}{ Her zaman } \\
\hline & n & $\%$ & n & $\%$ & $\mathbf{n}$ & $\%$ & $\mathbf{n}$ & $\%$ \\
\hline $\begin{array}{l}\text { Cinsel sağlığı ilgilendiren konularda yapılan eğitim } \\
\text { toplantılarına katılma }\end{array}$ & 59 & 15.8 & 246 & 65.8 & 45 & 12.0 & 24 & 6.4 \\
\hline $\begin{array}{l}\text { Üreme organlarını hastalık belirtileri yönünden } \\
\text { dikkatlice izleme }\end{array}$ & 12 & 3.2 & 146 & 39.0 & 162 & 43.3 & 54 & 14.4 \\
\hline $\begin{array}{l}\text { Cinsel sağlıkla ilgili yazılı ve görsel basında çıkan } \\
\text { haberleri takip etme }\end{array}$ & 25 & 6.7 & 201 & 53.7 & 117 & 31.3 & 31 & 8.3 \\
\hline $\begin{array}{l}\text { Üreme organlarının temizliği konusunda sağlık } \\
\text { görevlilerinden bilgi alma }\end{array}$ & 65 & 17.4 & 209 & 55.9 & 72 & 19.3 & 28 & 7.5 \\
\hline
\end{tabular}

Elde ettiğimiz verileri yapılan diğer çalışmaları desteklemektedir. $\mathrm{Bu}$ bulgular doğrultusunda hemşirelik öğrencilerinin farkındalık düzeylerinin yüksek olduğu söylenebilir.

Enfeksiyonları önlemede ve perine hijyeninin sağlanmasında iç çamaşırının her gün değiştirilmesi oldukça önemlidir [7]. Çalışmada öğrencilerin yarısının $(\% 53,5)$ iç çamaşırlarını her gün değiştirdikleri saptanmıştır. Türkiye'de üniversite öğrencileri ile yapılan çalışmalarda iç çamaşırını her gün değiştiren kesimin \%38 ile \%47 arasında değişkenlik göstermektedir $[1,2,4,14,15,16]$. Bu bulgular göz önüne alındığında öğrencilerin iç çamaşırı değiştirme sıklığının her gün olması gerekliliğinin farkında olma durumlarının yeterli düzeyde olmadığı söylenebilir. İç çamaşırının rengi, türü, yıkama, kurutma ve değiştirme sıklığı, saklama koşulları çok önemlidir İç çamaşırların renginin kaynatmaya ya da yüksek 1sıda yıkanmaya uygun olan beyaz renkte ve pamuklu tercih edilmesi gerekmektedir [14, 17]. Öğrencilerin \%89,8'inin iç çamaşırlarını çamaşır makinesinde, \%69,5'inin deterjan ile yıkadıkları saptanmıştır. 
Tablo 3. Öğrencilerin Genital Hijyen Yönelik Uygulamaları

\begin{tabular}{|c|c|c|c|c|c|c|c|c|}
\hline & \multicolumn{2}{|c|}{$\begin{array}{l}\text { Hiçbir } \\
\text { zaman }\end{array}$} & \multicolumn{2}{|c|}{ Bazen } & \multicolumn{2}{|c|}{ Sık sık } & \multicolumn{2}{|c|}{ Her zaman } \\
\hline & n & $\%$ & $\mathbf{n}$ & $\%$ & $\mathbf{n}$ & $\%$ & $\mathbf{n}$ & $\%$ \\
\hline \multicolumn{9}{|l|}{ Mensturasyona İlişkin Uygulamalar } \\
\hline Mensturasyonda hazır ped kullanma & 1 & 0.3 & 10 & 2.7 & 31 & 8.3 & 332 & 88.8 \\
\hline Mensturasyonda bez kullama & 298 & 79.7 & 36 & 9.6 & 14 & 3.7 & 26 & 7.0 \\
\hline Sürekli günlük ped/ara bezi kullanma & 51 & 13.6 & 138 & 36.9 & 90 & 24.1 & 95 & 25.4 \\
\hline Mensturasyonda duş şeklinde banyo yapma & 5 & 1.3 & 56 & 15.0 & 103 & 27.5 & 210 & 56.1 \\
\hline Ped değiştirmeden önce elleri yıkama & 21 & 5.6 & 114 & 30.5 & 112 & 29.9 & 127 & 34.0 \\
\hline Ped değiştirdikten sonra elleri yıkama & 6 & 1.6 & 8 & 2.1 & 49 & 13.1 & 311 & 83.2 \\
\hline \multicolumn{9}{|l|}{ Genital Hijyene İlişkin Uygulamalar } \\
\hline Tuvalete girmeden önce elleri yıkama & 30 & 8.0 & 158 & 42.2 & 104 & 27.8 & 82 & 21.9 \\
\hline Tuvalete girdikten sonra elleri yıkama & 1 & 0.3 & 9 & 2.4 & 31 & 8.3 & 333 & 89.0 \\
\hline Önden arkaya doğru & 238 & 63.6 & 55 & 14.7 & 38 & 10.2 & 43 & 11.5 \\
\hline Taharetlendikten sonra tuvalet kağıdı ile kurulanma & 5 & 1.3 & 20 & 5.3 & 60 & 16.0 & 289 & 77.3 \\
\hline \multicolumn{9}{|l|}{ Enfeksiyon belirtilerine İlişkin Uygulamalar } \\
\hline Pis kokulu akıntı olduğunda doktora gitme & 62 & 16.6 & 150 & 40.1 & 82 & 21.9 & 80 & 21.4 \\
\hline Üreme organlarında kaşıntı olduğunda doktora gitme & 82 & 21.9 & 160 & 42.8 & 67 & 17.9 & 65 & 17.4 \\
\hline
\end{tabular}

Literatürde sentetik deterjanların vulvitise neden olduğu belirtilmektedir. Genital bölgenin hassas yapısından dolayı ideal olan iç çamaşırlarının sabun ya da sabun tozu ile yüksek 1sıda yıkanmasıdır [13]. Timur'un 2010 yılında yaptığı çalışmasında öğrencilerin iç çamaşırını sabunla yıkama oranı $(\% 33,3)$ yarıdan daha azdır [13]. Yağmur'un 2007 yılında yaptığı çalışmada kadınların \%75,0'i iç çamaşırını bir işleme tabi tutmadan (çamaşır suyu, ön yıkama, kaynatma v.b.) doğrudan çamaşır makinesinde yıkadığını belirtmiştir [18]. Araştırma bulguları diğer iki çalışmayla benzerlik göstermektedir ve çalışmalar elde edilen bulguları destekler niteliktedir. Öğrencilerin cinsel sağllğı ilgilendiren konularda yapılan eğitim toplantılarına katılma durumlarına bakıldığında \%6,4'ünün her zaman katıldığı saptanmıștır. Ünal ve arkadaşlarının 2017 yılında yaptıkları çalışmada öğrencilerin \%5,1'i her zaman cinsel sağlığı ilgilendiren eğitim toplantılarına katıldıklarını ifade etmiş̧lerdir [14]. Her iki çalışmada da cinsel sağlığı ilgilendiren konularda eğitim alma oranı oldukça düşüktür. Bu oranların düşük düzeyde olması öğrencilerin eğitimlere açık olmaması hem kendi sağlığı hem de toplum sağlığı açısından büyük bir öneme sahiptir. Çalışmada öğrencilerin \%14,4'ünün her zaman üreme organlarını hastalık belirtileri yönünden dikkatlice izlediği ve \%7,5'inin her zaman üreme organların temizliği konusunda sağlık görevlilerinden bilgi aldığı saptanmıştır. Bilgi düzeylerinin az olan, sağllk görevlilerinden bilgi almayan öğrencilerin cinsel sağlık hakkında yayınlanan haberler ve görsel basını kullanma oranlarının \% 8,3 olduğu belirlenmiștir. Ünal ve arkadaşlarının 2017 yılında yaptıkları çalışmada öğrencilerin \%28,2'sinin üreme organlarını hastalık belirtileri yönünden dikkatlice izlediği ve cinsel sağlık hakkında yayınlanan haberler ve görsel basını kullanma oranlarının \%12,8 olduğu belirlenmiş̧tir [14]. Her iki çalışmada da bu oranın oldukça düşük olduğu görülmektedir. Bu konularda topluma eğitim verecek olan hemşirelik öğrencilerinin daha donanımlı olmaları için hemşirelik eğitimi kapsamında üreme sağlığı ve cinsel sağlık derslerinin konulması gerektiği düşünülmektedir.

Hazır ped kullanımının absorban oluşu, iç çamaşırları koruyuculuğu, rahatlık, hijyenik oluşu, günlük aktiviteyi kısitlamamak gibi bazı avantajları mevcuttur. Yapılan çalışmada öğrencilerin büyük bir çoğunluğu $(\% 88,8)$ mensturasyonda hazır ped kullanırken sadece $\% 7,0$ 'sinin bez, $1 / 4$ ise $(\% 25,4)$ sürekli günlük ped kullanmaktadır. Türkiye'de üniversite öğrencileri ile yapılan çalışmalarda öğrencilerin \%80,0'ninden fazlasının ped kullandığı belirlenmiş̧tir $[1,14,15,16]$. Çalışmada öğrencilerin ped kullanma oranlarının yüksek olması genital hijyen açısından olumlu bir sonuçtur.

Öğrencilerin büyük çoğunluğunun (\%56,1 her zaman, $27,5 \%$, sı sık) mensturasyonda duş şeklinde banyo yaptığı ve $(\% 83,2)$ ped değiştirdikten sonra ellerini yıkadıkları, \%34,0'ünün her zaman ped değiştirmeden önce ellerini yıkadıkları bulunmuştur. Enfeksiyonları önlemenin en önemli ve en basit yolu su ve sabunla ile ellerini yıkamaktır. El yıkama alışkanlığı aile içinde erken çocukluk döneminde elde edilir. Öğrencilerin banyo yapma durumu ve ped değiştirdikten sonra ellerini yıkamaları sevindiricidir. Ancak ped değiştirmeden önce ellerini yıkamamaları oldukça düşüktür. Çeşitli çalışmalar, mensturasyonda duş şeklinde banyo yapmanın ve ped değiştirdikten sonra ellerini yıkamanın öğrenciler arasında yaygın bir uygulama olduğunu bildirmiştir $[1,2,4,14,15,16]$.

Araştırmaya katılan öğrencilerin yarısının $(\% 21,9$ her zaman, \%27,8 s1k sik) tuvalete girmeden önce, çoğunluğunun $(\% 89,0$ her zaman) tuvaletten sonra ellerini yıkadığı, \%63,6'sının hiçbir zaman genital temizliğini önden arkaya yapmadığı, sadece \% 11,5 'inin her zaman olarak cevap verdikleri ve \%77,3'ünün her zaman taharetlendikten sonra tuvalet kağıdı ile 
kurulandıkları saptanmıştır. Hemşirelik fakültesinde öğrenim gören öğrencilerin önden arkaya doğru taharetlenme konusundaki bilgi ve uygulamalarının yetersiz oldukları görülmektedir. Türkiye'de farklı gruplarda yapılan benzer çalışmalarda da çalışmamıza benzer şekilde azımsanmayacak oranlarda yanlış şekilde genital temizliğinin yapıldığı görülmektedir (Lise $\% 45,5[19], \% 27,4$ [20]; üniversite öğrencileri \%16,5 [4], $\% 16,6$ [3], \%19,2 [13], \%40,9 [14], \%55,2 [15], \%30,8 [16]; evli kadınlar \%76,0 [20], \%62,4 [7]). Genital yol enfeksiyonlarının önlenmesinde uyulması gereken hijyenik kurallardan birisi de doğru taharetlenmedir. Yapılan çalışmalar göz önüne alındığında her gruptan kadının bu konuda eğitilmesi gerektiği görülmektedir. Özellikte kadınların genital hijyen konusunda eğitilmelerine katkı sağlayacak olan hemşirelik fakültesinde öğrenim gören öğrencilerin bu konuda eğitimlerine önem verilmesi gerektiği düşünülmektedir.

Çalışmamızda tuvalete girmeden önce el yıkama oranı (\%21,9 her zaman, \%27,8 sik sik) yapilan benzer çalışmalara göre daha yüksektir. $[3,4,7,12,13,14,15$, 16, 19, 20, 21]. Farklı gruplarda yapilan benzer çalışmalar değerlendirildiğinde aradaki eğitim farklılıklarına rağmen yine de Türk toplumunda, tuvalete girmeden önce el yıkama alışkanlığının yaygın olmadığ söylenebilir.

Öğrencilerin \%40,0’’nın (\%21,4 her zaman, \%21,9 s1k sık) pis kokulu akıntı olduğunda doktora gittikleri; $\% 35,0$ 'inin (\%17,4 her zaman, \%17,9 s1k s1k) üreme organlarında kaşıntı olduğunda doktora gittiği saptanmıştır. Ardahan ve Bay 2009 yılında yaptıkları çalışmada öğrencilerinin \%66,0'sının, "hijyenime dikkat ederim ve en kısa zamanda doktora giderim" şeklinde

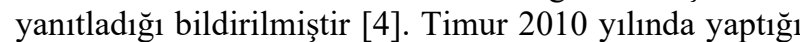
çalışmada öğrencilerin \%68,0'inin anormal vajinal akıntı şikayeti olduğunda doktora başvurmadığını saptamıştır [13]. Ünal 2017 yılında yaptığı çalışmada kız öğrencilerin \%7,0'si cinsel bölgede kaşıntı olduğu her zaman doktora gittiğini, \%12,8'ise pis kokulu akıntı olduğunda her zaman doktora gittiğini, \%2,6's1 ise düzenli olarak her zaman kadın doğum uzmanına gittiklerini belirtmişlerdir [14]. Elde edilen bulgular doğrultusunda anormal bir durum karşısında doktora gitme oranlarının düşük olduğu ve yeterince önem verilmediği anlaşılabilir.

\section{Sonuc}

Kız öğrencilerin genital hijyene yeterince özen göstermediği, genital hijyen davranışları, bilgi alma, yardım aramada yeterli olmadığı ve bu konudaki farkındalıkları düşük olduğu sonucuna varılmıştır. Öğrencilerin genital hijyen davranışları ve sağlık sonuçları konusunda bilgi ihtiyaçlarının olduğu söylenebilir. Kadınların genital hijyen konusunda eğitilmelerine katkı sağlayacak olan hemşirelik fakültesinde öğrenim gören öğrencilerin başta genital hijyen olmak üzere, aile planlaması, üreme sağlığı ve cinsel yolla bulaşan hastalıklar hakkında bilgilendirme eğitimleri verilmelidir. Düzenlenecek eğitim programlarında, farkındalık oluşturan, kalıcı davranış değişikliği oluşturabilen, aktif katılımın gerçekleştiği, etkili eğitim yöntem ve tekniklerinin kullanılmasına mutlaka dikkat edilmelidir.

\section{Referanslar}

1. Sevil, S, Kevser O, Aleattin, U, Dilek, A, Tijen, N, An Evaluation of the relationship between genital hygiene practices, genital infection, Gynecology Obstetrics, 2013, 3(6), 1-5.

2. Özdemir, S, Ortabağ, T, Tosun, B, Özdemir, Ö, Bebiş, H, Hemşirelik yüksekokulu öğrencileirnin genital hijyen hakkındaki bilgi düzeylerinin ve davranışlarının değerlendirilmesi, Gülhane Tip Dergisi, 2012, 54, 120-128.

3.Ünsal, A, Universite okuyan kız öğrencilerin genital hijyen davranışları, Furat Sağlık Hizmetleri Dergisi, 2010, 5, 79-93.

4. Ardahan, M, Bay L, Hemșirelik yüksekokulu 1.ve 4. sinıf öğrencilerinin vajinal akıntı ve bireysel hijyen hakkındaki bilgi düzeyleri, Ege Tip Derg /Ege Journal of Medicine, 2009, 48, 33-43.

5. Eğilmez, P, Saraçoğlu, F, Yılmaz, N, Kadınların hijyen uygulamaları, Kadın Doğum Dergisi, 2003, 2, 131-133.

6. Low, N, Broutet, N, Adu-Sarkodie Y, Barton P, Hossain M, Hawkes S, Global control of sexually transmitted infections, Lancet, 2006, 368, 2001-2016.

7. Dasıkan, Z, Kılıç, B, Baytok, C, Kocairi, H, Kuzu, S, Genital akıntı şikâyetiyle polikliniğe başvuran kadınların geninal hijyen uygulamaları, Gümüşhane Üniversitesi Sağllk Bilimleri Dergisi 2015, 4(1), 113-124.

8. Koştu, N, Beydağ, KD, Jinekoloji polikliniğine başvuran kadınların genital hijyen davranışları, Atatürk Üniversitesi Hemşirelik Yüksekokulu Dergisi, 2009, 12(1), 66-71.

9. Özkan, S, Demir, Ü, 15-49 Yaş doğurganlık çağı kadınlarda vajinitisin tanımlanmasında hemşirenin etkinliğinin belirlenmesi ve vajinitisin oluşmasına neden olan faktörlerin incelenmesi, Sağllk ve Toplum 2002, 12 (4), 54-61.

10. Temel, M, Metinoğlu, M, Tekirdağ İline bağlı I ve IV nolu sağlık ocaklarına bassvuran 15-49 yas kadınlarda genital hijyen uygulamalarının incelenmesi, İ.U.F.N. Hemşirelik Dergisi, 2007, 15, 91-99.

11. Aytaç, A, Eryılmaz, Y, Vajinal akıntı tanılama formu (VATF) kullanılarak konulan tanıların uyum analizi, Maltepe Üniversitesi Hemsirelik Bilim ve Sanatı Dergisi, 2009, 2, 22-33.

12. Ünsal, A, Özyazıcıoğlu, N, Sezgin, S, Doğu Karadeniz'deki bir belde ve ona bağlı dokuz köyde yaşayan bireylerin genital hijyen davranışları, Anadolu Hemşirelik ve Sağlık Bilimleri Dergisi, 2010, $13,12-19$

13. Timur, S, Bir üniversite öğrenci yurdunda kalan kız öğrencilerin genital hijyen davranışları, e-Journal of New World Sciences Academy, 2010, 5, 39-48

14. Ünal, KS. Hemşirelik öğrencilerinin genital hijyen davranışları bilgi düzeylerinin belirlenmesi. Journal of Current Researches on Health Sector 2017; 7(1), 23-36.

15. Bilgiç, D, Yüksel, P, Gülhan, H, Şirin, F, Uygun, H, Üniversitede yurtta kalan kız ögrencilerin genital hijyen davranışları ve sağlık sonuçları, Acıbadem Üniversitesi Sağlık Bilimleri Dergisi, 2018 , Online Early

16. Topuz, S, Duman, NB, Güneș, A, Sağlık bilimleri fakültesi birinci sınıftaki kız öğrencilerin genital hijyen uygulamaları, Turkish Journal of Clinics and Laboratory, 2015, 6(3), 85-90.

17. Kısa, S, Taşkın, L, Ankara'da bir ana çocuk sağlığı ve aile planlaması merkezine başvuran 15-49 yaş evli kadınlarda vajinal enfeksiyon gelișmesini etkileyen davranışsal ve sosyo-demografik risk faktörleri, Sağllk ve Toplum Dergisi, 2007,17(1), 69-84.

18. Yağmur, Y, Malatya ili Fırat Sağlık Ocağı bölgesinde yaşayan 15-49 yaș kadınların genital hijyen davranışları, TSK Когиуиси Hekimlik Bülteni, 2007, 6(5), 325-330.

19. Tartaç, Y, Özkan, S, Lise öğrencilerinin menstruasyon hijyen konusunda bilgi/tutumları ve eğitimin etkinliğini değerlendirme, Gazi Medical Journal, 2011, 22, 27-32.

20. Koyun, A, Özpulat, F, Özvarış, ŞB, Bir eğitim programı geliștirme ve değerlendirme süreci: ortaöğretim kız öğrencileri için "genital hijyen" eğitim programı, Gümüşhane Üniversitesi Sağlık Bilimleri Dergisi, 2013, 2, 443-59.

21. Palas, P, Karaçam, Z, Kadınların tutukevinde bulunmalarının genital hijyen uygulamalarına etkisi, Anadolu Hemşirelik ve Sağllk Bilimleri Dergisi, 2013, 16, 27-35. 
http://edergi.cbu.edu.tr/ojs/index.php/cbusbed isimli yazarın CBU-SBED başlıklı eseri bu Creative Commons Alıntı-Gayriticari4.0 Uluslararası Lisansı ile lisanslanmıştır.

(ㄷ) $(1) \Theta$ 